\title{
Conserving and Sustaining Culture through Traditional Dress
}

\author{
POTLAKO L. P. DISELE ${ }^{1}$, DAVID J. TYLER ${ }^{2}$, E.J. POWER ${ }^{3}$
}

\section{ABSTRACT}

The government of Botswana through its National Policy on Culture (2001) and the National Ecotourism Strategy (2002) is committed to preserving national culture and historical heritage. The policy stipulates that valuable heritage must be preserved and developed in order to foster a sense of national identity, pride and unity. It is necessary to reformulate cultural values and valuing processes, in order to better understand the Setswana culture and its meaning in material objects. To this end, dress as one of the valuable material culture objects is essential for signifying and expressing subtle cultural value and social relationships. The intimate link between people and their traditional dress lies at the core of ethnic identity, and has assumed a higher level of significance among consumers and tourists who collect symbolic items. A specific emphasis on a national traditional dress seems to be lacking in Botswana. This paper argues that there is need to restore traditional dress in Botswana, which would serve as a symbol of national identity and cultural heritage. The paper is based on the findings of a study that explored the historical underpinnings of national dress in Botswana, and how national dress could be used to sustain culture.

\section{KEYWORDS:}

Traditional dress, culture, conserving, sustaining, symbolic, national identity, Setswana.

\section{Introduction}

\footnotetext{
${ }^{1}$ Department of Family and Consumer Science, University of Botswana E-mail:diselp@ mopipi.ub.bw.

${ }^{2}$ Reader in the Department of Clothing Design \& Technology, Hollings Faculty, Manchester Metropolitan University, Old Hall Lane, Manchester. E-mail:d.tyler@mmu.ac.uk.

${ }^{3}$ Senior lecturer Department of Clothing Design \& Technology, Manchester Metropolitan University Emailj.power@mmu.ac.uk
} 
The use of dress as an expression of social and cultural identity has increased in many countries. Through dress, people are able to express their social and cultural identities. Studies (Hamilton \& Hamilton, 1989; Eicher \& Sumberg 1995; Kuma-Kpobee, Power \& Otieno, 2008). have established that there is a link between dress and societal differentiation. They recognise the importance of dress to culture and its potential to reveal connections between people and their cultural identity. In spite of the significance of dress, dialogue on traditional dress at national level seems to be lacking in Botswana; an anomaly that is out of sync with the desire to preserve national culture and historical heritage. Therefore, it is necessary to understand the meanings and significance of the national traditional dress, and its relationship with cultural identity. Thus, Batswana will only be in a position to adopt a holistic notion for preservation of their cultural artefacts, by first establishing the relationship between traditional dress and salient values and meanings.

\section{Literature Review and Theoretical Grounding}

Literature on dress indicates that there are many ways in which people identify with their ethnic groups or nationalities, and that dress has an important link with culture. Studies from different ethnic groups have for a long time shown that certain types of people's preferences of dress were those clothes whose meanings were in agreement with their sense of identity. For example, the traditional dress of Highland in Scotland (Chapman, 1995), the Kalabari dress ensemble (Eicher \& Erekosima, 1995), traditional marriage dress in Nigeria (Rene, 1995), Kaba and Slit of Ghana (Dogbe, 2003); (Kuma-Kpobee, Power \& Otieno, 2008), tribal Herero dress in Botswana (Durham, 1992), and burial societies' dress 'seaparo' in Botswana (Ngwenya, 2002). They assert that different ethnic groups and sub-cultures have dress that denotes their culture. Edensor (2002) supports this observation by indicating that dress becomes a marker of cultural identity and is used to express identity in national ceremonies or cultural activities. In this regard, material culture artefacts are then manipulated unconsciously or consciously as a way of ensuring that they are aligned to ethnic group or nation's values and beliefs (Hamilton \& Hamilton, 1989; Eicher \& Sumberg, 1995; Kaiser, 1998).

A similar observation was made by Roach-Higgins and Eicher (1992:6) in reference to characteristics of dress that communicate identities of an individual about their society's social structure. This includes "belief systems that shape moral and aesthetic standards for dress..." and 
those that define what is acceptable in relation to beliefs about modesty, or what is considered appropriate and inappropriate dress. Scholars point out that these belief systems vary from society to society and even between sub-groups within the same society. Michelman (2005) also points out that the issues of modesty vary culturally; what is considered proper dress conduct in one culture may not necessarily be so in another. This is true also with respect to the perceived definition of dress, and the linkages between dress and culture. This paper explores the possibility of restoring traditional dress in Botswana, as a symbol of national identity and cultural heritage.

\section{The meaning of dress in context}

Dress as defined by Roach-Higgins and Eicher (1992) is an ensemble of body modification and supplements. This definition is a holistic approach to dress, encompassing everything that concerns the body; body decorations; and disfiguring of the body; which includes tattooing, colouring of the skin, hairstyles, piercing of ears, clothing or garments and accessories. Through social interaction of the individuals and their dress, identities, attitudes, cultural values and beliefs are announced or communicated (Roach-Higgins \& Eicher 1995; Trollip, 1995; Ngwenya, 2002; Crane, Hamilton \& Wilson, 2004). According to Roach-Higgins and Eicher (1995:14-15), dress characteristics for identities are dynamic, and change in relation to materials, technology, economy, or societal concerns for conserving the natural environment, and/or belief systems that "shape moral and aesthetics standards for dress". Furthermore, changes may occur as a result of the fact that the properties or characteristics of a particular or type of dress "no longer serve as identity..." (p.16). Thus, the characteristics and significance of dress to culture cannot be rooted to the past, but rather evolve with time and the changing use of dress.

According to Eicher and Sumberg (1995) ethnic dress is linked to ethnicity and ethnic identity. Thus, dress is significant to ethnic identity, as it is used to communicate identity of individuals among groups, and of a group. Various scholars argue that ethnicity embraces the ideas of group cohesion and has boundaries that can distinguish members of a group from nonmembers. This unity shares a common heritage including language, dress, beliefs, conduct and the general way of life. Ethnic dress as Eicher and Sumberg (1995:302) suggest, "indicates common or shared ways of dress that identify a group of people who share a common background and heritage". 
According to some scholars, tradition is culture-inclined. It is a learnt behaviour or practice that is slow to change and tends to be confined. Tradition involves knowledge and customs that are handed over through generations (Sperber, 1996). They constitute "an item or action(s) inherited intact from the past" (Taylor, 2002:201). Jirousek (1997) supports these claims and views tradition as the notion of the past, bound by social order and rules, and implies relatively slow change. Furthermore, it implies simplicity and close community. Thus, the choice of dress in such settings is bound to be limited.

Baldwin, Longhurst, MacCracken, Ogborn and Smith (1999) argue that, tradition is culturally constructed, and in the process of construction and reconstruction, some things are included or excluded. What used to be valued in the past may not necessarily be the case in certain situations. One may cite the example of the 'kilt', an item of dress that used to be confined to a particular ethnic group, but has since been accepted to represent the Scottish culture. Along the same lines, Rabine (2002) argued that tradition has an element of continuity, transformation through time and tends to exhibit influence from other cultures. Rabine (2002:29) further observed that "influences from elsewhere are not perceived to fill an absence ... but to be threaded into an ongoing cultural project that for centuries has been building even as it is unravelling and continues, tragically to do so". Tradition therefore, is a practice or custom and knowledge transmitted through generations. Despite it being slow to change, tradition undergoes transformation and reconstruction, which denotes consistency and continuity.

\section{Traditional dress and culture heritage}

Traditional dress may be defined as the ensemble and design which is representative of the community or is identified with a particular cultural behaviour and particular cultural values. Scholars argue that even though traditional dress is believed to be unchanging, the developments that have occurred in dress challenge these definitions, due to the fact that modifications have been observed. It has been found that as the community experiences economic changes and technological advancement due to increasing globalisation, in some situations the changes in traditional dress may lose purity and authenticity (Eicher \& Sumberg, 1995). Therefore, the physical features of the dress are modified in the process and may take the new form whilst keeping with the traditional culture of social identity and gendered roles (Jirousek, 1997). Traditional dress is coded to suit different occasions or place or situation. This changes its 
meanings with time and depending, on the statement the group intends to convey. Individual ethnic groups ascribe their meanings, which may sometimes be conflicting. The changes may also be on the style of dress items (Rabine, 2002). Eicher and Sumberg (1995) view traditional dress as the same as ethnic dress with regard to the way people are identified, when they share a common background and cultural heritage. Although traditional dress as a symbol is used to identify ethnic identity or any other form of identity, in a particular society, it differs from national dress, which is linked to the concept of nation-state with political boundaries where a set of attire may represent several ethnic groups within a given country. Nevertheless, depending on the specific group of people and their historical background, traditional dress and national factors may coincide (Eicher \& Sumberg, 1995).

From the definitions and understandings considered, it can be argued that, traditional dress cannot be pinned to the past nor can it be an item that does not change. As traditional dress is considered part of a dynamic culture, it is liable to be affected by the changes that occur within which that culture. Meanings and usage of traditional dress therefore change with the passage of time, reconstruction and repackaging of ideas about culture. This study therefore, concurs with the views of scholars who consider traditional dress as changing depending on times, values of the group and new forms of culture (Kuma-Kpobee, Power \& Otieno, 2008). In this manner, traditional dress is liable to undergo a process of cultural transformation and the styles adopted to be authenticated to the values of a particular culture or group.

\section{Dress in Botswana}

Dress in Botswana is generally influenced by different cultures (Durham, 1993; Denbow \& Thebe, 2006). It would appear that there is no evidence of a national traditional dress. However, Batswana traditional dress prior to contact with European missionaries and traders was fashioned with fur and skins, indigenous bronze, leather bands of rhinoceros hide, and bracelets from elephant teeth, which were used as ornaments. Batswana also adorned themselves with specularite and ochre (letsoku). According to Denbow and Thebe (2006), these clothing items denoted status and in some cases, they had ritual connotations. For example, some of them were used as protective medicine against sickness, harm and jealousy. The $19^{\text {th }}$ century saw increasing use of garments made of cloth including 'ankle-length dresses with tight bodices, gathered at the waist and worn with layers of petticoats. Popular fabrics were the dark blue or brown German 
print (leteise), which became a commonly used cloth among Batswana. Headscarves (ditukwi in Setswana) adopted from Afrikaans (doeke) were worn on the head, and small fringed plaid blankets became iconic of Batswana women, particularly for special occasions involving parties, weddings and funerals. Batswana increasingly adopted European dress, while the original traditional dress is now a peculiar feature of the traditional dance groups (Denbow \& Thebe, 2006).

Traditional dress changes and undergoes transformation over time, as is the case with values and forms of culture. In the process, the traditional dress styles may be authenticated to the values of a particular culture or group. The intention of this study therefore is to understand their precepts on the traditional dresses that exist, and the symbolic meanings relating to conferring identities, rather than to pass judgment on the perceived views of the respondents. To this end, the study explored the possibility of restoring elements of the various forms of traditional dress, as it is understood in contemporary Botswana.

The inductive interpretive approach to social research is useful in determining what is meaningful to Batswana, around the issue of dress in this case. This approach often provides deeper understanding on issues of culture, and how people perceive their material culture artefacts. It allows for grounding of the field findings.

\section{Research Methodology}

Qualitative strategies were adopted for this study because of their resourcefulness in understanding people's perceptions and the meanings attached to the question of dress. The study sought to gather information that exposed opinions, precepts underlying the meaning and significance of dress as constructed by people (Bryman, 2004). An interpretive work through the grounded theory by Strauss and Corbin (1994) was pertinent to the study of the social and cultural aspects of restoring traditional dress in Botswana. This facilitated an understanding of symbolic meanings, emergent and unanticipated conceptual contributions, as well as interpretation based on informants' opinions. In order to understand the views of the individuals in relation to the restoration of traditional forms of dress, the study focused on Batswana's 
perceptions of dress, historic traditional dress, the relationship of dress to culture, and whether traditional dress has a place in contemporary Botswana. The study covered six geographical areas, which were drawn from the Local Authorities and focused on four districts and two urban areas in Botswana.

Data were gathered through observation of rites of passage (including marriage, enthronement of chiefs and cultural events where traditional dress is likely to be worn), museums and curio shops. Observations were conducted between May and August 2005 in seven areas: Gaborone, Gantsi, Kasane, Mochudi, Molepolole Tlokweng, and Tsootsha. The purpose of these observations was to find out whether traditional dress exists, and to generate information relating to events during which traditional dress is worn or used. Hamilton and Hamilton (1989: 17) state that viewing the phenomenon from the people's point of view 'encourages the researcher to avoid, to the extent possible, imposing one's values and interpretations inappropriately'. Documentation of historic artefacts and explanation of dress used during rites of passage events offered holistic explanations of events, and an understanding of the relationships between various factors being researched. Under these conditions, data produced have a chance of being context-sensitive. Thus, through participating and observing the different events, the study was able to identify different types and usages of traditional dresses and their symbolic significance to activities, the groups' culture, leadership empowerment and the general Setswana culture. The study used traditional dress items documented, and displayed in museums and curio shops, as well as photographs and videos of dress worn during weddings and chief enthronement celebrations.

In-depth interviews were held with key informants, politicians, married couples, traditional dress manufacturers. Focus group discussions were also conducted with a diverse range of individuals from the various ethnic groups. This made it possible to explore the various forms of traditional cultural dress, as well as the similarities and differences between the cultural artefacts. Both the individual interviews and focus group discussions were tape recorded, and later transcribed verbatim into Setswana, in order to preserve their original meaning. The research was able to unearth direct experiences on the selected event in detail. The findings reflect detailed views as reported by the people (Bryman, 2004).

\section{Sampling procedures}


Multi-phase sampling was adopted for selecting the primary unit (sites). Purposive sampling through referrals was employed to select the sites and villages, access informants and select participants for the focus groups, while the key events including marriage rites, enthronement rites and a cultural event were conveniently chosen. Opportunistic sampling was used to identify all the events observed in this study, and this resulted in five marriages, one enthronement of a chief and one cultural event. Some of the key informants were selected purposively, whereas others were selected through snowball opportunistic sampling. The primary protocol for inclusion was that first, the villages were chosen because they represented the Local Authority (LA's) headquarters where most of the gatekeepers, including paramount chiefs or tribal leaders, the relevant senior LA staff who could grant permission to access the areas and assist in identifying informants and focus group members could be found. Secondly, in the main villages, the study ensured inclusion of the older members of the community who are vested with historical information regarding traditional dress and cultural values. Thirdly, young people were chosen as potentially, they are the future users of the traditional dress. Lastly, the political leaders were included in this study, due to their influential role in policy development.

The selection of key informants was done through the assistance of the traditional leadership and through referrals. The Local Authorities' community social workers assisted in identifying the focus group discussants, the adult and youth groups with whom they work. Political leaders were identified through the political parties which were willing to participate in the study. Identification of clothing manufacturers was done through the facilitation of the Ministry of Commerce and Industry. The sample comprised 183 informants. These consisted of 74 key informants constituting elders who are well versed in historical information; 8 political leaders; 9 clothing manufacturers and 92 adults and youths. The latter group constituted participants in the focus group discussions.

\section{Data collection and analysis}

Grounded theory was utilised to generate themes from the interview findings through successive levels of data analysis (Strauss \& Corbin 1998). The Grounded Theory Approach was first developed and explained by Glaser \& Strauss (1967), and was expanded by Strauss and Corbin 
1994). Grounded theory is a method in which analysis of data is generated without first developing priority themes or assumptions. As a qualitative inductive approach, in this study it facilitated identification of emergent themes and establishment of themes between categories (Strauss \& Corbin, 1998). The approach helped to enhance the understanding of the phenomena of traditional dress in Botswana, in light of its meanings and significance. Transcripts were read through several times. Differences and similarities of the view-points expressed in the identification of key issues and common themes were noted. Analysis of data was done in two phases; during data collection and afterwards.

The study employed the microanalysis technique suggested by Strauss and Corbin (1998). This required that first, some key informants' interviews, and one adult focus group interview which were conducted on the first day of the field work be read repeatedly, line-by line to gain a deeper understanding, and to generate initial categories that formed the basis for the data analysis. All the themes and categories identified were compiled separately and compared in order to establish the relationships, as well as the similarities and differences. The concepts were then classified according to these relationships for further grounding (Strauss \& Corbin, 1998). Several concepts and categories which emerged from the interview were first clarified with the key informant and some of the members of the focus group. This allowed the researchers to further explore the categories for clarity and depth. A three stage method: open, axial and selective coding adopted from Strauss and Corbin (1998) was used alongside the Interpretative Phenomenological Analysis (IPA), suggested by Smith \& Osborn (2003), which assisted in generating the format used for data analysis.

\section{Research Findings and Discussion}

Verbatim statements are used to illustrate the perceptions of the respondents and discussants. The findings in this study suggest that there is an intimate link between dress and culture. Although the majority of the respondents indicated that there is no national traditional dress for Batswana, the findings revealed that some of the dress items such as shawls, headscarves; trilby or fedora hats and tailored jackets for men are popular in most parts of the country, as signifiers of respect for occasions, place, self; as well as for bereavement. The relationship between these dress items and the predominant Setswana culture seem highly evident. According to the respondents, these 
dress items are used in marriage rites or funerals as a form of identity. Furthermore, they are significant in the transformation of an individual's status.

\section{Perceptions about, and meanings of dress}

The findings of this study revealed that there is no single definition of dress. The findings concur with the views of Eicher, Everson \& Lutz (2000) regarding knowledge about dress. This knowledge is drawn from an array of 'anecdotes and accounts'. Furthermore, societies differ in terms of forms of dress and in meanings. The general conception from this study defines dress in terms of functions performed by dress. These include covering the body for nakedness, protecting the body from physical injury and psychological ills. Dress is also believed to confer identity and status. Similarly, dress is anything worn on the body to adorn it. This conception does not define dress specifically and holistically. It limits dress only to garments, and excludes the other body supplements and modifications suggested by Roach-Higgins and Eicher (1992). However, the respondents' perceptions partly support the notion held by several scholars (Roach-Higgins \& Eicher 1992; Entwistle, 2000) that recognise the properties and expressive abilities of dress.

In defining dress, the respondents were of the view that dress is a cover for the body, as it conceals the body from nakedness, and protects the private parts from being seen in public. Furthermore, they maintained that dress has biblical and sexual connotations. They also indicated that the feeling of shame when naked is linked with indecency, particularly in public places, and that there is an association between modesty and immodesty vis a vis, cultural value, as it is understood in the Botswana context. Thus, it is generally considered morally wrong and indecent to expose one's body in public. The perceptions concur with the explanation by Horn and Gurel (1975), which shed light on some of the reasons why people first wore clothes, and perceptions about the original functions of clothing. Similar views were also expressed by some informants. One political leader commented that:

But, from the other perspectives, dress has been used primarily to shield one's body, particularly those parts of the body that are viewed traditionally or within the traditional social or community settings to be private or too private to be seen either by the self or 
within those situations where the intimate other self is permitted to view the naked body [POL 03].

These findings seem to reflect a number of factors including the original purpose of dress, and the pre-colonial cultural values, norms and expectations, as well as the changing socialisation patterns, as they relate to dress and its symbolism.

Traditional dress is sometimes referred to as folk dress which, for rural people implies slow changing and non-fashionable ethnic dress (Eicher \& Sumberg, 1995). It would appear that there is no uniform view on traditional dress, and the conception of traditional dress differed from informant to informant. Some informants regard traditional dress as an unchanging notion, while others concur with Eicher \& Sumberg (1995) that traditional dress is cultural, and that it depicts societal culture, and can be passed from generation to generation. Moreover, the informants generally viewed traditional or national dress in terms of appropriateness and respectability. The statements below demonstrate what the society considers appropriate and acceptable behaviour with regard to dress conduct in general, which in turn, tends to inform views about traditional dress. Although the expectations are not written as statutes or law, the society defines what is acceptable. One view expressed during an adult focus group discussion stated that:

What we see these days is shameful; some girls walk the streets wearing very short dresses or skirts, exposing their thighs to be admired by the opposite sex. This is not acceptable in our culture; short dresses are for children [AFG04: D4].

Most of the respondents and discussants emphasised the importance of acceptable appearance, in terms of what society expects with regard to the way a person should conduct himself/herself in social locations such as the kgotla. This thinking is in sync with Kaiser's (1998), in relation to the observation that in some instances, an individual's appearance is influenced by the prevailing cultural beliefs and values. In addition, Roach-Higgins and Eicher (1992) claim that the characteristics of dress that communicate identities of an individual about society's social structure include "belief systems that shape moral and aesthetic standards for dress..." 


\section{The significance of dress for cultural identity and heritage}

Some of the informants were of the opinion that social appearance and respect are at the core of the definition of traditional dress, suggesting that there is a particular way that Batswana ought to conduct themselves with regard to what they wear, and how they wear it. They regard simplicity, comfortable fitting garments and none revealing clothes as culturally acceptable characteristics of dress. Thus, conformity to this expectation is a necessary pre-condition for respect for self, family and the socio-cultural values. Accordingly, deviation from these expectations is regarded as culturally unacceptable. Hence, there appears to be a general objection to miniskirts, and tight fitting and revealing garments. A common assumption is that such forms of dress perpetuate rape and indecent behaviour, and is regarded as a way of 'self-advertising', to try to attract the opposite sex. Thus, the notion of an aggressive trader is evoked, in the Setswana saying that 'mmapatsi phokwana o tsamaya a ntshitse', meaning that the nature of an aggressive trader is to display his/her wares). In one way, this perception can be said to be against the whole concept of 'botho' (social contract of mutual respect, responsibility and accountability that members of society have toward each other).

Moreover, the emphasis on concealing nakedness is an indicator of good Tswana cultural values. It would appear, from the definition of dress above that, the expectations of the society and its moral convictions are linked to what can be described as good cultural values. In a similar context, Kaiser (1998), Rubinstein (2001) and Michelman (2005) observed that what is modest in one society may not be so in another. Thus, the degree of modesty differs from culture to culture, depending on the particular society's beliefs, norms and values. The scholars indicate that every society forms opinions about clothing on the basis of appropriate and expected behaviour. Flugel (1971) and Michelman (2005) also note variations in concepts of modesty in different cultural and belief systems, societies and situations.

The significance and particularity of type of dress is linked to the societal norms or customs of Batswana. For instance, the usage of shawls or the covering of shoulders, headscarves and calf-length garments for women, and the wearing of jackets for men are key artefacts that anyone attending kgotla meetings and funerals would be expected to wear. These specific garments convey meaning of respect for the authority of the chief, the kgotla, occasion,

self, society and culture. These garments also reflect their individual and social status, such as 
manhood or womanhood. However, when the same garments are used in marriage rituals, they enable the individuals to construct their identities as married people, and establish their roles and responsibilities, as has been the case through the generations. Moreover, the respondents' perceptions of dress with regard to their social and cultural meanings correspond with the work of Michelman (2005) on Kalabari culture, which demonstrates that the cultural celebration of womanhood, childhood and physical maturity is characterised by dress and body modifications to suit the particular occasion.

Some scholars hold that the meanings that are communicated through the various forms of dress pose either positive or negative perceptions amongst some sections of the society (Kaiser, 1998; Roach-Higgins and Eicher, 1995). For instance, the wearing of mini-skirts was particularly despised by the older respondents and some of the youths who regarded these garments as indecent, and as a misrepresentation of the Tswana culture. They equated the wearing of such things to being unclothed (go sa tswala). This view was held by both the male and the female respondents regarding mini-skirts and tight-fitting and revealing clothes for men or women. They further argued that although women's pants seem to be acceptable as organisational uniforms (such as police uniforms, corporate wear in government and provide institutions), they are not part of the Tswana culture. The respondents generally showed some resentment, believing this clothing item to be culturally unacceptable. Hence, the women who wear them are believed to have 'crossed traditional gender boundaries', and are seen to be equating themselves to men, as Kaiser (1998:454) also found out.

\section{Preservation of cultural heritage through dress}

On the question of the form of dress that was adopted after contact with Europeans to replace the 'skin' traditional dress, there was considerable difference of opinion. However, most of the informants refuted the existence of a general or nation-wide traditional dress. Some adult respondents claimed that there is a Tswana-style garment that is worn by women nation-wide. They considered a dress with full gathers on the waist (mosese wa lesethana), puff sleeves, waist bands or sashes attached on the sides and tied at the back, and round or square or sweetheart neckline, as conforming to the idea of a national Tswana dress. The same description was applied to a sleeveless pinafore dress worn with a cotton blouse and a headscarf. It was further mentioned that the style (mosese wa lesethana) is a predominant form of Tswana-style 
traditional dress for both women and girl-children. Both the pinafore and the full dress, which are rarely worn nowadays, were fashioned from cotton fabrics with small prints, and resembled the missionary dress styles. Whilst the dress was thought to be a Tswana traditional dress, not all Batswana women wore it. Durham's (1995) study supports the existence of a Tswana-style dress that resembles a contemporary or more or less international style made of cotton print fabrics. However, the use of blankets or shawls and headscarves according to the findings of this study is not meant for every woman, but is reserved for mature and married women. Young adults and girls only put on something (be it a jacket, jersey or scarf) on their shoulders when they go to the kgotla or when they attend a funeral. The findings further indicate that the small blankets, shawls and headscarves are highly symbolic, as they signify the individual's status of womanhood, maturity and marriage. It was also pointed out that men initially wore khaki trousers and shirts, and ultimately adopted Western-style suits.

It would appear that prior to the arrival of European missionaries and traders, traditional dress in Botswana was fashioned from skins, and accessories were made from local plants and ostrich eggs. The skin dress comprising mothikga le motlokolo/phaeyana/mojamboro and cloaks (mokuru/sekhutlana/kobo ya metlhose) was worn by women, while motseto with mothibampana/mapunda and chiziba was worn by men. Girls wore makgabe/makabi, and tshega/seope was commonly worn by boys amongst most Batswana groups. The style was similar for most of the dress items, but was labelled differently from ethnic group to ethnic group. Some of the views reproduced below, regarding existence of any adopted traditional dress after contact with Europeans bear out this assertion:

"There is no dress code that we can truly say is for Botswana" [YFG01: D5]

"I honestly do not think Batswana can claim to have a traditional dress" [AFG01: D6

"I cannot figure out that which we can call our own" [KI: 34]

“Batswana over-embraced the English culture..." [YFG02: 8]

"To be honest with you, I do not think we have anything, but at least in this respect the chiefs have maintained their traditional ceremonial dress code" [POL: 01]

"In the same way that the British or Europeans dress, Batswana also dress" [KI: 16]

Following Batswana's contact with European missionaries and traders, their form of dress underwent transformation, due to a number of factors. These factors included changes in 
ecological and environmental regulations on hunting of wildlife; the monetary value of livestock; accessibility of global goods, products and overall technological development.

When the informants were asked if there is a need to restore traditional dress in Botswana they expressed a general consensus, affirming the need to have a traditional dress in Botswana, which they felt is important for promoting cultural and national identities. The comments captured Table 1 demonstrate that the majority of respondents from all the categories supported the restoration of traditional dress.

Table 1: The need to have a national traditional dress in Botswana

\begin{tabular}{|l|c|c|}
\hline \multicolumn{1}{|c|}{ Respondents } & Restore & Do not restore \\
\hline KI & 72 & 2 \\
\hline POL & 5 & 1 \\
\hline CLOM & 8 & 2 \\
\hline AFG & 58 & 2 \\
\hline YFG & 30 & 10 \\
\hline Total & 173 & \\
\hline
\end{tabular}

The respondents have been coded according to status

$\mathrm{KI}=$ Key Informants; POL $=$ Political Leaders; CLOM = Clothing Manufacturers; AFG $=$ Adult Focus Groups and YFG = Youth Focus Groups

The respondents spoke about the importance of preserving culture, ethnic and national identity, and the need to enhance national unity through a national traditional dress. It was further indicated that a national traditional dress would serve to identify Batswana and differentiate them from other nationalities, thereby legitimising their cultural identity, and that a traditional dress could help instil and accord expressions of belonging to a particular ethnic group - both at community and national level. The following responses were typically expressed: 
Yes, it is important since it is said a nation without culture is a lost nation. I personally think that we have to do a lot of soul searching now. For instance, Basotho, Mapondo in South Africa, Nigerian and Indians have their traditional dress that distinguishes them from other nationalities [AFG01:D6]

Mma, it is high time we have something that we can pride ourselves with. We see Nigerians, Ghanaians and Zambians wear their dress such that we even buy it calling it African attire. This is a sign that we want to have something. Even in the Olympics you easily identify them with their dress; when they are called, you will not only see the flag but also they will be in their cultural dress. But for us, you see a flag and people would be in suits and fashionable outfits, nothing to show that we are Batswana. Mma, it is essential that we have our own traditional dress as Batswana to identify us; make us proud and we identify with it [YFG02:D5].

The respondents also showed a general quest for identity, by citing the current usage of garments made of German print (leteise) and African attires for special occasions, such as cocktail parties of cultural ceremonies and Botswana days. One informant, a politician commented thus:

I think it is what is accepted as traditional fabric for most groups in Botswana such as Bakgatla, Bakwena, Balete, Batlokwa, or Bangwaketse; in general, I think leteise has always been accepted within those tribes. Therefore, we may say it is somewhat semiofficial for most Setswana ethnic groups [POL 07].

The clothing manufacturers also supported the quest for a national traditional dress. They noted that there is generally a high demand for traditional dress and fabrics. One clothing manufacturer commented that:

There is a remarkable demand of cultural garments in Botswana. Garments decorated with material culture objects and those made from leteise are observable in our businesses. A lot of our customers nowadays wear garments that depict their culture or are more African. My observations are that, nowadays people seem to have a quest for products with an inclination towards their own culture and most designers now tap this 
niche. I want to believe that if traditional dress can be restored, the clothing industry will benefit a lot. You know, people now want be identified with their own culture. Both the older and the younger generations are now searching for something that can identify them as Batswana. Despite my customers' demands, as you can see my products, my inspiration is based on culture and material culture objects [CLO 08].

In acknowledging the need to restore traditional dress that can define Batswana and their culture, most of the respondents and discussants felt that this would also facilitate the generational transfer of the historical and cultural heritage. They further suggested that national unity could be nurtured and the dress in question could promote the unification of Batswana. The other views indicated that the restoration of the traditional dress could also cascade into other benefits, as some of the statements below indicate:

It is very important. We should be identifiable by our dress as a nation. It would also be very useful in teaching our history and conserving our culture as Batswana [KI 12].

We have lost our culture such that our children do not have an idea of what was worn and we cannot blame them for conducting themselves the way they do. It is very important that we reflect on our culture and resuscitate it, document it for the benefit of the generations to come [KI 27].

...If we were to restore our traditional dress as our cultural identity, it would increase our chances for unity. We would become very patriotic and solidarity would be highly esteemed [POL 03].

In supporting their call for the restoration of traditional dress, some respondents considered the possible benefits that could accrue to the tourism and clothing industries, as indicated below:

It is important especially for identity. This would even be very important in future because currently tourism is emphasised, and this will in the end be an enterprise that 
will enhance the economy. Many people would benefit from this business. For example, photographers could take pictures of the traditional dress and sell them for inclusion in magazines. Also people could advertise Botswana by wearing this dress [YFG05: D3].

Much as I produce contemporary garments, there is a high demand for cultural/traditional garments nowadays. I believe if traditional dress can be encouraged, it will boost the clothing industry in this country as people are for things that represent their culture. I am already benefiting from this line of products [CLO 03].

Along similar lines, Denbow and Thebe (2006) highlighted an increasing trend in usage of the leteise after Botswana's independence. Consistent with the findings of this study, the scholars hold that the increased usage of the leteise on special occasions and cultural festivities, would enhance cultural values and national pride. However, Denbow and Thebe (2006) did not examine issues pertaining to the restoration of traditional dress, as a form of identity and preservation of cultural heritage. They simply focused on general issues regarding culture and customs of Batswana.

\section{The way forward: Potential implementation strategies}

The need to restore national traditional dress has implications for the types of fabric, materials, style and colour that could be used. When respondents were asked about what materials, style and colour they would prefer for their traditional dress, a number of fabrics were mentioned. Figure 1 below shows the respondents' fabric preferences. The high preference of the leteise is linked to its performance, functionality, ease of manipulation during construction, and popularity amongst Batswana. Besides, the leteise fabric was considered versatile for both men's and women's garments. A fabric designed with the Botswana National Flag colours was suggested by few Key informants (KI), Politicians (POL) and Youth focus groups (YFG). Linen or cotton fabrics decorated with cultural designs were mentioned by some clothing manufacturers; whilst only a few respondents felt that there could be one style but the choice of fabric be left to individuals. 
Figure.1: Material choice for the anticipated traditional dress

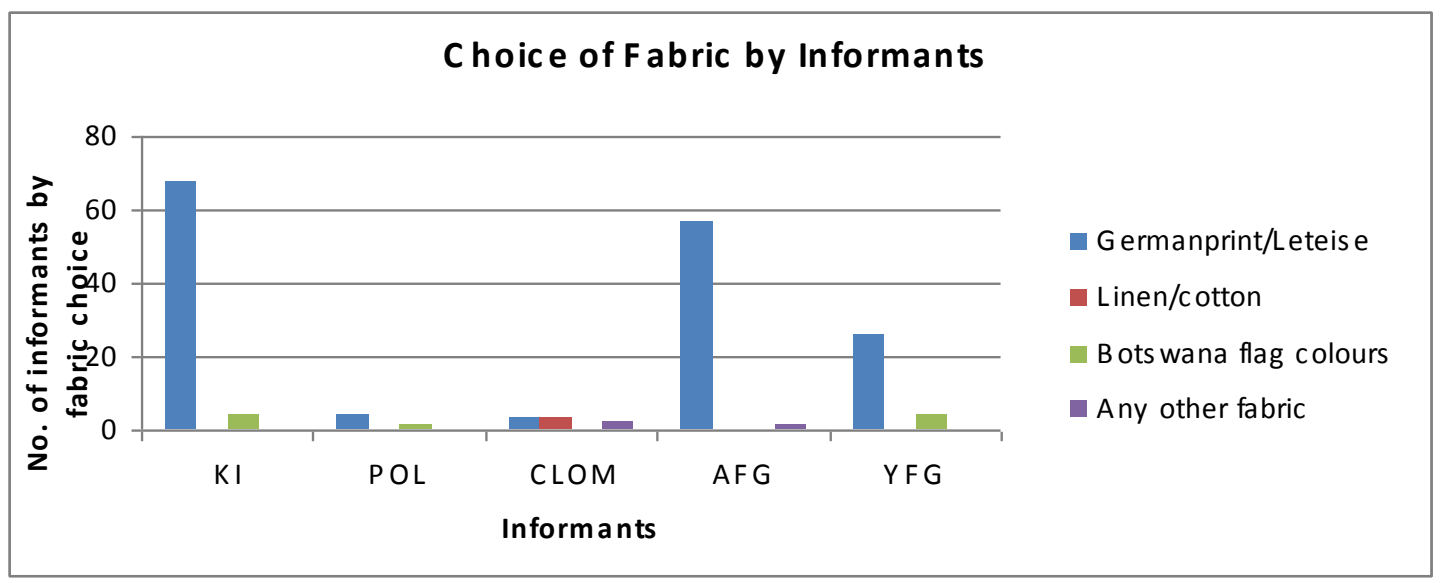

The respondents were asked to express opinions regarding a timeframe for restoration, and recommended countrywide consultations. Almost all the respondents in the categories interviewed felt consultations within the communities would be imperative. Whilst consultation was suggested by most respondents, others indicated that this study could be instrumental in the restoration of traditional dress and inform the policy on culture. The desire to have the traditional dress in place by 2016; which is the target of Botswana's long-term vision was evident. Some of the respondents emphasized the importance of embracing their cultural values through a dress that will distinguish them from other nations, particularly where Botswana envisages transformation across the broad spectrum.

Whilst some of the respondents concur with the idea of comprehensive consultation, they strongly uphold the view that the leteise fabric be utilised in any traditional dress and suggest that the discussion should be focused on style and the leteise print. Many believed that there is a relationship between the leteise and the Setswana culture. The cloth type was introduced by the European colonizers after 1810, and has been part of local culture since then.

\section{Conclusion}

It seems apparent from the discussion that the definition of dress as perceived by those interviewed has overtones of morality. It is also linked to cultural values that stem from socialisation. Yet, from the perspective of some of the respondents, dress is not wholly inclusive; but, rather a product worn to cover the body from nakedness and stave off adverse weather 
conditions. The findings also suggest a strong relationship between dress and the Tswana culture, in terms of social appearance, respect, moral values, status and generally acceptable conduct. The society appears to embrace simplicity, good fitting and none revealing clothes as cultural standards. Hence, conformity to this expectation denoted respect for self, family and society's cultural values. Miniskirts, tight fitting and revealing garments which deviate from these expectations are considered culturally unacceptable. The attires of Indians, Bazezuru, Baherero and Mbanderu serve as relevant examples of national dress, and Batswana can easily identify with these. As the country attains 50 years of independence, the idea of a national traditional dress is important to Batswana as nation. Indeed, the current traditional dress as worn by the various ethnic groups in the country indicates a viable way forward, but there is need for further debate for example, on the relevance of the cultural renaissance through weddings, funerals, dikgafela (thanks giving festivals) and others.

Although there is no common traditional dress in Botswana today, some of the dress items discussed in this paper could be regarded as traditional as they are linked to societal norms or customs (shawls, headscarves, jackets) and can be situational. Evident also is that some ethnic groups have their traditional dress which identify and differentiate them; confer status, womanhood or manhood, and bestow roles and responsibilities.

As indicated by the results, Batswana yearn for the establishment of traditional dress, in one form or another. The leteise was favoured to take this role, by most respondents. Furthermore, most of the participants were in support of developing a traditional dress, as a form of identity for Batswana, and as a way of preserving their material artefacts. Thus, through the recognition of traditional dress, as highlighted above, Batswana hope to achieve cultural renewal, and to promote national identity. Some participants also favoured the restoration of the traditional dress for commercial reasons - they believe it would promote business opportunities within the tourism industry. Invariably, respondents recommended further research that would involve nation-wide consultations on the type, form, design, and appearance of what would be acclaimed as the Botswana traditional national dress.

\section{References}


Baldwin, E., Longhurst, B., McCracken, S., Ogborn, M. \& Smith, G. 1999. Introducing Cultural Studies. England: Prentice Hall.

Botswana Government. Ministry of Labour and Home Affairs. 2001. National Policy on Culture. Gaborone: Government Printers.

Bryman, A. 2004. Social Research Methods. 2nd edn. Oxford: Oxford University Press.

Chapman, M. 1995. "Freezing the Frame: Dress and Ethnicity in Brittany and Gaelic Scotland in Eicher, J. B. Ed. Dress and Ethnicity: change across space and time. Oxford: Berg, pp7-28.

Crane, T.C., Hamilton, J.A \& Wilson, L.E. 2004. Scottish Dress, Ethnicity and Self-identity, Journal of Fashion Marketing, 8 (1), pp. 66-83.

Denbow, J \& Thebe, P. C., 2006. Culture and Customs of Botswana. Westport: Greenwood Press.

Dogbe, E. 2003. Unravelled Yarns: Dress, Consumption and Women's Bodies in Ghanaian Culture, Fashion Theory: The Journal of Dress, Body and Culture, 7 (3-4), pp.377-395.

Durham, D. L. 1993. The Image of Culture: being Herero in a Liberal Democracy (Botswana). PhD Dissertation, University of Chicago.

Durham, D. L. 1995. The Lady in the Logo: Tribal Dress and Western Culture in a Southern African Community, in Eicher, J. B. Ed. Dress and Ethnicity: Change across Space and Time. Oxford: Berg, pp183-194

Eicher, J. B. \& Roach-Higgins, M. A. 1995. Dress, Gender and Age, in Roach-Higgins, M. A. Eicher, J. B. \& Johnson, K. K. Ed. Dress and Identity. New York: Fairchild Publications, pp102106

Eicher, J.B. \& Erekosima, T.V. 1995. Why do they Call it Kalabari? Cultural Authentication and Demarcation of Ethnic Identity,' in Eicher, J.B. Ed. Dress and Ethnicity. Oxford: Berg.

Eicher, J.B., Evenson, S. L. \& Lutz, H. A. (2000) The Visible Self. 2nd edn. New York: Fairchild Publications.

Eicher, J.B \& Sumberg, B. 1995. World Fashion, Ethnicity, and National Dress, in Eicher, J.B. Ed. Dress and Ethnicity: Change across Space and Time. Oxford: Berg.

Edensor, T. 2002. National Identity, Popular Culture and Everyday Life. Oxford: Berg.

Entwistle, J., 2000. The Fashioned Body. Cambridge: Polity Press.

Glaser, B. G. \& Strauss, A. L. 1967. The Discovery of Grounded Theory. Chicago: Aldine Publishing Company.

Hamilton, J. A. \& Hamilton, J. W. 1989. Dress as a Reflection and Sustainer of Social Reality: a Cross Cultural Perspective. Clothing and Textile Research Journal 7 (2), pp. 16-22.

Horn, M.J. \& Gurel, L.M. 1981. The Second Skin. 3rd ed. Boston: Houghton Mifflin Company.

Jirousek, C. A. 1997. From "Traditional" to Mass Fashion System" Dress among Men in a Turkish Village, Clothing and Textile Research Journal, 15 (4), pp. 203-215.

Kaiser, S. 1998. The Social-psychological Aspects of Clothing: Symbolic Appearances in Context, 2nd ed. New York: Macmillan Publishing Company.

Kuma-Kpobee, M., Power, J. \& Otieno, R. 2008. Utilisation of Traditional Dress: The Case of Slit and Kaba in Ghana. Textile Institute $86^{\text {th }}$ World Conference. Conference Proceedings: Hong Kong. 
Michelman, S. O. 2005. Modesty and Immodesty, in Damhorst, M. L., Miller-Spillman, K. A. and Michelman, S. O. Eds. The Meaning of Dress. New York: Fairchild Publications, page numbers.??

Ngwenya, B.N. 2002. Gender, Dress and Self-Empowerment: Women and Burial Societies in Botswana, African Sociological Review, 6 (2), pp.1-27.

Rabine, L. W. 2002. The Global Circulation of African Fashion. Oxford: Berg.

Renne, E. P. 1995. Becoming a Bunu Bride: Bunu Ethnic Identity and Traditional Marriage Dress in Eicher, J. B. Ed. Dress and Ethnicity: Changes across Space and Time. Oxford: Berg, pp. 117-13.

Roach-Higgins, M. A. \& Eicher, J. B. 1992. Definition and Classification of Dress, in Barnes, R. and Eicher. J. B. Eds. Dress and Gender: Making and Meaning in Cultural Context. Oxford: Berg, pp. 8-28.

Roach-Higgins, M. A. \& Eicher, J. B. 1992. Dress and Identity. Clothing and Textiles Research Journal, 10 (4), pp. 1-8.

Roach-Higgins, M. A. \& Eicher, J. B. 1995. Dress and Identity, in Roach-Higgins, M. A. Eicher, J. B. \& Johnson, K. K. Ed. Dress and Identity. New York: Fairchild Publications, pp7-18

Rubinstein, Ruth. P. 2001. Dress Codes: Meanings and Messages in American Culture. 2nd ed. Colorado: Westview Press.

Smith, J.A., Jarman, M. \& Osborn, M., Ed. 2003. Doing Interpretative Phenomenological Analysis, in Murray, M. and Chamberlain, K. Qualitative Health Psychology: Theories and Methods. London: SAGE Publications, pp. 51-80.

Sperber, D. 1996. Explaining Culture: a Naturalistic Approach. Oxford: Blackwell.

Strauss, A. \& Corbin, J. 1994. Grounded Theory Methodology: an Overview, in Denzin, N. K. and Lincoln, Y. S. Ed. Handbook of Qualitative Research. Thousand Oaks: Sage Publication, pp1-18.

Strauss, A. \& Corbin, J. 1998. Basics of Qualitative Research: Techniques and Procedures for Developing Grounded Theory. 2nd ed. Thousand Oaks: Sage Publications.

Taylor, L. 2002. The Study of Dress History. Manchester: Manchester University Press.

Trollip, A.M. 1995. Meaning of Blankets, Towels and T-shirts in the Context of Acculturation. South African Journal of Ethnography, 18 (4), pp. 150-151. 